\title{
MANAJEMEN PENDIDIKAN KARAKTER DI POLITEKNIK AL ISLAM DAN UNIVERSITAS ISLAM NEGERI SUNAN GUNUNG DJATI BANDUNG
}

\author{
Karmilah \\ Politeknik Al Islam Bandung \\ Karmilah39304@gmail.com
}

\begin{abstract}
ABSTRAK
Pentingnya pendidikan karakter dalam membentuk manusia yang berkualitas menjadi ketertarikan penulis untuk mengkaji sejauhmana implementasi pendidikan karakter yang sudah dilaksanakan di beberapa perguruan tinggi di Bandung. Pendekatan penelitian ini menggunakan pendekatan kualitatif dengan metode studi kasus yang mengamati keberjalanan program pendidikan karakter di Universitas Islam Negeri Sunan Gunung Djati Bandung dan Politeknik Al Islam Bandung. Teknik pengumpulan data melalui wawancara, observasi, dan dokumentasi. Berdasarkan hasil penelitian diketahui bahwa manajemen program pendidikan karakter kedua perguruan tinggi tersebut sudah berjalan dengan cukup baik yaitu dengan adanya Renstra, program kerja tahunan, dan laporan akhir bulan kepada pihak-pihak terkait. Kegiatan-kegiatan yang berbasis karakter dan pengawasan yang berkelanjutan. Faktor-faktor pendukung dari kedua perguruan tinggi tersebut hampir sama yaitu kedua perguruan tinggi tersebut mempunyai atmosfer keagamaan yang kental dengan norma-norma islam, begitu pun dengan faktor penghambatnya hampir sama yaitu pekembangan arus globalisasi yang berpengaruh terhadap perkembangan karakter dan terbatsnya sumber daya manusia. Agar Pendidikan karakter dapat menghasilkan lulusan yang berkualitas sesuai dengan standar dan indikator yang ada, maka dari itu, perlu penulis merekomendasikan beberapa hal yaitu :1) Semua yang terlibat harus memahami hakikat pendidikan karakter 2) Ada keterlibatan dari semua pihak 3) Perlu adanya sarana dan prasarana yang mendukung 4) Perlu adanya komunikasi antara pihak lembaga dengan stake holder.
\end{abstract}

Kata kunci: Karakter, Manajemen, Pendidikan

\begin{abstract}
The importance of character education in building a qualified human resource became the author's interest to determine the extent to which character education implementation education has been carried out in several universities in Bandung. This research approach used a qualitative approach with a case study method that observed the sustainability of character education programs at UIN Bandung and Politeknik Al Islam Bandung. Techniques for collecting data through interviews, observations and documentation. The result showed that the management of character education program from the two tertiary institutions has been running well both with the existence of annual programs, strategic plans and annual final reports to the relevant parties. The supporting factors of the two tertiary institutions were almost the same, namely the two universities have a religious atmosphere that was thick with Islamic norms and even with almost the same inhibiting factors, namely the development of globalization flows that influenced character development. In order for character education to produce quality graduates in accordance with existing standards and indicators, the authors need to recommend several things, 1) must understand the nature of character education 2) There was involvement of all parties 3)
\end{abstract}


Need for supporting facilities and infrastructure 4) Need communication between the institution and

Keywords: Character, Education, Management

\section{PENDAHULUAN}

Data UNICEF tahun 2016 menunjukkan bahwa kekerasan pada sesama remaja di Indonesia diperkirakan mencapai 50\%. Sedangkan dilansir dari data Kementerian Kesehatan RI 2017, terdapat 3,8\% pelajar dan mahasiswa yang menyatakan pernah menyalahgunakan narkotika dan obat berbahaya. Menurut kepala Badan Narkotika Nasional Bapak Jendra Heru Winarko, beliau menyebutkan bahwa ada peningkatan penyalahgunaan narkotika dikalangan remaja yaitu sebesar 24 sampai $28 \%$. World Drugs Reports 2018 yang diterbitkan United Nations Office on Drugs and Crime (UNODC), menyebutkan sebanyak 275 juta penduduk di dunia atau 5,6\% dari penduduk dunia (usia 15-64 tahun) pernah mengonsumsi narkoba. Sementara di Indonesia, BNN selaku focal point di bidang Pencegahan dan Pemberantasan Penyalahgunaan dan Peredaran Gelap Narkoba (P4GN) mengantongi angka penyalahgunaan narkoba tahun 2017 sebanyak 3.376.115 orang pada rentang usia 10-59 tahun. Sedangkan angka penyalahgunaan Narkoba di kalangan pelajar di tahun 2018 (dari 13 ibukota provinsi di Indonesia) mencapai angka 2,29 juta orang. Salah satu kelompok masyarakat yang rawan terpapar penyalahgunaan narkoba adalah mereka yang berada pada rentang usia 15-35 tahun atau generasi milenial.

WHO atau World Health Organization (2017) menyatakan bahwa masa remaja merupakan masa transisi yang kritis sebagai kunci berkembangnya pengalaman baru yaitu usia 10-19 tahun, Masa remaja dihadapkan pada masa dorongan ingin mencoba untuk mengonsumsi alkohol, narkoba, rokok, atau bahkan seks, sehingga risiko akan terjadinya kehamilan yang tidak diinginkan.

Masalah kenakalan remaja adalah masalah kita bersama yang harus dipikirkan oleh semua pihak, tidak hanya oleh pemerintah, tapi juga oleh pihak sekolah atau perguruan tinggi, masyarakat, dan keluarga itu sendiri, karena remaja atau pemuda merupakan generasi emas penerus bangsa yang akan melaksanakan pembangunan bangsa ini, apalah jadinya suatu bangsa kalau para pemudanya tidak mempunyai akhlak yang baik, maka pendidikan karakter sangat diperlukan disemua jenjang pendidikan untuk membekali para peserta didik agar mempunyai sikap dan perilaku yang baik, tentunya harus disertai manajemen yang baik pula untuk menghasilkan output yang berkualitas.

Pendidikan karakter sebenarnya bukan hal baru, karena hal ini sudah diperkenalkan oleh Lickona, pencetus pendidikan karakter pada tahun 1992, Beliau mendefinisikan Pendidikan karakter sebagai upaya yang sungguh-sungguh untuk membantu seseorang memahami, peduli, dan bertindak dengan landasan nilai-nilai etis. Pendidikan karakter mengandung tiga unsur pokok yaitu mengetahui kebaikan (knowing the good), mencintai kebaikan (desiring the good), dan melakukan kebaikan (doing the good).

Seperti penelitiannya Hasanah (2020), merekomendasikan bahwa Manajemen pendidikan karakter di Perguruan Tinggi harus melibatkan seluruh dosen pengajar, staf dan stake holder yang terkait, agar semuanya dapat mengetahui, mendukung, dan mengawasi 
terlaksananya pendidikan karakter. Pendidikan Karakter di perguruan tinggi mempunyai tujuan untuk meningkatkan kualitas penyelenggaraan dan hasil pendidikan yang menghasilkan lulusan yang mengarah pada pencapaian pembentukan karakter dan mempunyai akhlak mulia yang sesuai dengan standar kompetensi lulusan.

Sedangkan menurut Darmawan (2014), Pelaksanaan pendidikan karakter di perguruan tinggi dapat diintegrasikan dalam kegiatan tridarma perguruan tinggi, yaitu pendidikan dan pengajaran, penelitian, dan pengabdian kepada masyarakat yang berkarakter. Pengintegrasian pendidikan karakter kedalam perkuliahan memerlukan perencanaan yang terpadu. Implementasi pendidikan karakter beserta monitoring dan evaluasinya pun harus sudah disiapkan dengan baik.

Penelitian lain (Irhandayaningsih,2013) menyatakan bahwa peran penting dari generasi muda Indonesia yaitu mahasiswa dalam pembangunan karakter adalah sebagai character enabler, character builders dan character engineer. Meskipun untuk melaksanakan ketiga peran tersebut, mahasiswa masih membutuhkan dukungan serta bantuan dari seluruh unsur bangsa termasuk pemerintah, tetapi esensi utama dari pembangunan karakter bangsa Indonesia menuju bangsa mandiri adalah pentingnya peran generasi muda sebagai komponen bangsa yang paling strategis posisinya dalam memainkan proses transformasi karakter dan tata nilai Pancasila di era global.

Menurut C Pattaro ( 2016) Character education aimed to connect students to the larger community, providing them with opportunities to engage in moral action. In this regard, the academic works focus mainly on service learning as a major element of character education initiative,artinya Pendidikan karakter bertujuan untuk menghubungkan siswa dengan komunitas yang lebih luas, memberikan mereka kesempatan untuk terlibat dalam kegiatan moral. Dalam hal ini ini, karya akademis terutama difokuskan pada pengajaran sebagai elemen utama prakarsa pendidikan karakter.

Kajian Penelitian yang terakhir (Sutarman;2020) The results of character education carried out in schools and in the community, carried out by students, teachers and others, in developing character education, training, preparation, and habituation are required. Conclusions made through discussion of the Environment, strategic planning, strategic implementation and evaluation that supports strengths, weaknesses, opportunities and defense, in determining strengths into opportunities, utilizing opportunities to overcome weaknesses, using strengths to protect and exploit weaknesses and challenges. Artinya Hasil pendidikan karakter yang dilaksanakan di sekolah maupun di masyarakat yang dilakukan oleh siswa, guru dan lain-lain, dalam pengembangan pendidikan karakter diperlukan pelatihan, penyiapan, dan pembiasaan. Kesimpulan diambil melalui pembahasan Lingkungan Hidup, perencanaan strategis, implementasi dan evaluasi strategis yang mendukung kekuatan, kelemahan, peluang dan pertahanan, dalam menentukan kekuatan menjadi peluang, memanfaatkan peluang untuk mengatasi kelemahan, menggunakan kekuatan untuk melindungi dan memanfaatkan kelemahan dan tantangan.

Berbeda dengan penelitian penelitian diatas, Dalam penelitian ini penulis tertarik untuk menganalisis pelaksanaan manajemen pendidikan karakter di Politeknik Al Islam Bandung dan Universitas Islam Negeri Sunan Gunung Djati Bandung,dimana kedua perguruan tinggi tersebut kental dengan nuansa Islam. Bagaimana kedua perguruan Tinggi tersebut 
melaksanakan manajemen pendidikan karakter di kampus, dari mulai planning, organizing, actuating, evaluating dan controlling.

\section{METODOLOGI PENELITIAN}

Penelitian ini menggunakan pendekatan Kualitatif dengan metode studi kasus. Menurut Cresswel (2015) ciri utama penelitian kualitatif adalah mengeksplorasi permasalahan dan mengembangkan pemahaman secara terperinci tentang fenomena sentral. Penelitian dilaksanakan di Politeknik Al Islam, Jalan Cisaranten Kulon No 120 Bandung dan Universitas Islam Negeri Sunan Gunung Djati, Jalan A.H Nasution No 150A Bandung. Perguruan tinggi tersebut dijadikan latar pembanding karena berbasis Islam, walaupun berbeda level, Politeknik Al Islam untuk jenjang D3 sedangkan UIN SGD jenjang S1, bahkan S2 dan S3. Peneliti mengambil data di Jurusan Kimia, karena untuk kegiatan pendidikan karakter hampir sama untuk semua jurusan. Penulis merasa tertarik untuk mengkaji kedua institusi tersebut untuk mengetahui keberjalanan manajemen pendidikan karakter

Instrumen penelitian ini adalah peneliti sendiri, karena menurut (Sugiyono. 2018) menyatakan bahwa instrument pada penelitian kualitatif adalah peneliti sendiri. Sumber data utama penelitian ini adalah wakil Direksi bagian akademik dan kemahasiswaan Politeknik Al Islam, kaprodi, dosen dan lima mahasiswa yang merupakan perwakilan dari ketiga jurusan. Sedangkan di UIN SGD sumber data diperoleh dari Ketua dan wakil ketua Jurusan Kimia dosen agama dan tiga mahasiswa. Data yang dikumpulkan berupa pendapat, ungkapan atau persepsi tentang manajemen pendidikan karakter yang sudah dilaksanakan, Maka dari itu jenis data penelitian ini adalah data primer. Pemilihan informan atau subjek penelitian berdasarkan kriteria yang ditetapkan oleh peneliti terlebih dahulu, yakni profil yang sudah mengetahui seluk beluk institusi tersebut lebih dari 2 tahun dan ikut terlibat langsung dalam kegiatan manajemen pendidikan karakter. Informan yang diambil adalah petinggi kedua institusi tersebuat yaitu wakil direksi yang menangani bidang akademik dan kemahasiswaan serta ketua jurusan kimia UIN SGD yang mengetahui kegiatan kegiatan yang dilakukan di institusi tersebut, kedua yaitu dosen agama yang mengelola langsung kegatannya, kemudian mahasiswa yang terlibat langsung dalam kegiatannya. Pengamatan dilakukan terhadap berbagai kegiatan baik kegiatan ekskul ataupun kegiatan yang sudah ada dalam kurikulum. Data sekunder dilakukan dengan menganalisis dokumen visi misi Politeknik Al Islam dan UIN Bandung, dokumen Renstra, Program kerja dan pedoman yang berkaitan dengan pendidikan karakter di Politeknik Al Islam dan UIN SGD Bandung, Validitas data menggunakan triangulasi sumber dan metode.

Untuk memperoleh data, dilakukan penelitian lapangan yang berlangsung selama enam bulan dari bulan Juli sampai bulan Desember tahun 2016, yang dilakuka dalam tiga tahap. Tahap pertama selama dua bulan pertama, peneliti bersilaturahmi dengan para juri kunci disana, untuk melancarkan langkah penelitian selanjutnya, tahap kedua peneliti melakukan wawancara dengan para informan yaitu 1 orang wakil direksi bagian akademik dan kemahasiswaan, dua orang dosen agama dan lima orang mahasiswa. Setelah itu melakukan studi dokumentasi untuk menggali informasi yang dibutuhkan, tahap ke tiga melakukan pengamatan langsung terhadap kegiatan kegiatan yang sudah disebutkan oleh para informan untuk membuktikan hasil wawancara dengan para informan.

Pengumpulan dan analisis data dilakukan secara terpadu, artinya analisis telah dikerjakan sejak di lapangan, yakni dengan penyusunan data atau bahan empiris (synthesizing) menjadi pola-pola dan berbagai katagori secara tepat. Bahan empiris yang terhimpun dianalisis dengan menggunakan tiga langkah analisis yang disarankan Miles dan Huberman (dalam denzim dan Lincoln, 1994) yaitu reduksi data, pemaparan bahan empiris dan penarikan kesimpulan dan verifikasi. 
Untuk memeriksa keabsahan data dalam kajian ini dilakukan kegiatan sebagai berikut: (a) melakukan triangulasi, (b) peer debriefing, (c) melakukan member check dan audit trial. Langkahlangkah triangulasi ini adalah (1) triangulasi sumber data, yang dilakukan dengan mencari data dari banyak sumber informan, yaitu orang yang terlibat langsung dengan kegiatan akademik (2) triangulasi pengumpul data (investigator) dilakukan penulis sendiri dengan cara mencari data dari banyak sumber informan, (3) triangulasi metode pengumpul data dilakukan dengan mengunakan bermacam-macam metode pengumpulan data (observasi, interview, studi dokumentasi,

maupun kelompok terpimpin (focus group), dan (4) triangulasi teori, dilakukan dengan cara mengkaji berbagai teori yang relevan, sehingga dalam hal ini tidak digunakan teori tunggal tetapi dengan teori yang jamak.

Analisis dilaksanakan sejak pengumpulan data dilaksanakan sampai penulisan artikel berakhir. Penulis juga melakukan diskusi teoritik dengan para pakar mengenai hasil sementara maupun hasil akhir penelitian ini, di antaranya: Prof, DR. Sofyan, Prof. DR. Sanusi dan Silmi Kapatan yang merupakan pakar dibidang pendidikan karakter, Untuk meningkatkan kredibelitas hasil penelitian, penulis melibatkan partisipan untuk memeriksa data dan interpretasi laporan hasil penelitian. Di samping itu, audit trial juga dilaksanakan untuk menguji keakuratan data melalui pemeriksaan data mentah (catatan lapangan, hasil rekaman, dokumen dan foto), hasil analisis data (rangkuman dan konsepkonsep), hasil sintesis data (tafsiran, simpulan, definisi, tema, interrelasi tema, pola hubungan dengan literatur, dan laporan akhir) dan catatan proses yang digunakan (metodologi, desain, strategi, prosedur, usaha keabsahan kredibilitas, dependabilitas, konfirmabilitas dan audit trail itu

\section{Hasil Penelitian}

\section{HASIL DAN PEMBAHASAN}

Berdasarkan hasil wawancara kepada direksi, ketua jurusan, dosen, dan mahasiswa, didapatkan beberapa temuan mengenai pelaksanaan manajemen penddikan karakter di Politeknik Al Islm dan UIN SGD Bandung sebagai berikut :

\begin{tabular}{ll}
\hline & Politeknik Al Islam \\
\hline Perencanaan & Pembuatan Renstra untuk kurun \\
& waktu lima tahun yang dibuat oleh \\
& para petinggi, Renstra tersebut \\
& diturunkan lagi ke Program kerja \\
& tahunan. Kemudian oleh para dosen \\
& dibuat lagi lebih spesifik dalam bentuk \\
& RPS dan RPP
\end{tabular}

Pengorganisasian
Pembagian kerja dilakukan berdasarkan sumber daya manusia yang tersedia. Yang perlu diperhatikan dalam pengorganisasian adalah kesesuaian dengan kompetensi, minat dan bakat agar dapat melaksanakan tugas dengan baik dan senang hati. Dalam pendidikan karakter, Dosen lebih banyak menerima tugas dalam

\section{UIN SGD}

Pembuatan Renstra untuk jangka waktu lima tahun yang dibuat oleh para petinggi, Rentra tersebut diturunkan lagi ke Program kerja tahunan. Kemudian dibuat lagi lebih spesifik dalam bentuk RPS dan RPP oleh para dosen. Karena UIN sudah berbentuk universitas, maka penjabaran pendidikan karakternya disesuaikan dengan jurusan masing masing dan orang yang terlibatpun lebih banyak

Rektor sebagai pimpinan universitas dibantu oleh para wakil memetakan tugas kepada para dosen dari tingkat fakultas sampai tingkat jurusan. Tugas tersebut dijabarkan lebih terperinci oleh bidang akademik dan kemahasiswaan dalam bentuk kegiatan 
menanamkan pendidikan karakter dengan mengintegrasikan karakter dalam mata kuliah yang diajarkan. Dosen lah yang lebih banyak berhubungan dengan mahasiswa. Direktur atau rektor sebagai penanggungjawab seluruh program kegiatan di kampus dibantu oleh wakil direktur bidang akademik dan kemahasiswaan.

\section{Pergerakan}

Pengendalian/ Evaluasi
1. Mata kuliah agama mempunyai SKS yang banyak dari semester 1 sd 6 2. Pesantren ahad untuk mahasiswa semester awal.

3. Pesantren Intensif untuk mahasiswa semester akhir

4. Perayaan hari hari besar Islam. Diisi dengan pengajian dan lomba-lomba 5. Pemotongan hewan qurban dan pembagian daging kepada masyarakat sekitar dan karyawan poltek sebagai wujud kepedulian sosial.

6. Setiap bulan ramadhan, setiap karyawan dianjurkan untuk mengikuti kajian rutin dan tadarus alquran 7. Pembagin sembako kepada masyrakat sekitar yng membutuhkan

\section{kegiatan yang berbasis}

karakter.

Mengacu pada Tri darma Perguruan Tinggi yaitu :1) Pendidikan dan pengajaran, kegiatannya berupa Praktek ibadah, tilawah, dan tahfidz yang bertujuan untuk meningkatkan pengetahuan mahasiswa dalam memahami dan menguasai baca tulis alQur'an dan terbiasa mengerjakan kegiatan ibadah.2) Bidang penelitian. Pengintegrasian antara keagamaan dan keahliankeahlian bidang umum dengan tujuan untuk merangsang mereka supaya dapat menggali potensi dan memotivasi mereka untuk belajar al-quran. 3) Bidang pengabdian pada masyarakat. Para mahasiswa yang tergabung dalam HMJ ( Himpunan Mahasiswa Jurusan ) mempunyai agenda selama 1 minggu sekali untuk mengamalkan ilmu yang mereka dapat dari kampus ataupun dari luar, selain itu juga ada acara kebersihan bersama dengan masyarakat, dan qurban, dengan tujuan supaya mereka dapat belajar bagaimana cara bersosialisasi, bekerja sama dan berinteraksi dengan masyarakat.

Evaluasi diadakan setiap bulan, untuk mengevaluasi keberjalanan setiap program yang telah dilaksanakan
Evaluasi dilaksanakan secara berkala dengan mengadakan rapat koordinasi setiap bulan dengan yayasan, direksi dan kepala unit, Pembahasan tentang pendidikan karakter tidak dibahas 
secara terpisah namun terintegrasi

dengan bidang akademik dan

Kemahasiswaan. Dalam Pembahasan

Renstra, pengkajian Visi dan misi

sangatlah penting, karena dengan visi

dan misi akan membentuk profil

lulusan dan akan melahirkan kegiatan

kegiatan yang berbasis karakter,

\section{Pembahasan}

Perencanaan merupakan hal yang penting dalam keberhasilan pendidikan, Perencanaan meliputi apa yang akan dicapai, bagaimana mencapainya, waktu yang akan ditempuh, biaya yang diperlukan, dan jumlah sumber daya yang dibutuhkan (Arifin; 2019). Sedangkan menurut Robins dan Coulter (2012) Perencanaan adalah tindakan yang meliputi penetapan tujuan, penetapan strategi untuk mencapai tujuan tersebut. Menurut Rahman (2019) perencanaan dalam manajemen Pendidikan berbasis karakter seperti termaktub dalam manajemen pendidikan berbasis sekolah dimana kepala pimpinan mempunyai otoritas untuk mengatur institusinya. Kalau di Perguruan tinggi terletak pada rektor atau direktur yang mempunyai otoritas penuh dalam mengatur kebijakan di institusinya

Perencanaan yang telah dilakukan oleh Politeknik Al Islam dan UIN Bandung sudah melaksanakan perencanaan sesuai dengan teori tersebut yaitu dengan membuat Renstra selama 1 sampai lima tahun kedepan, Dalam renstra tersebut dirumuskan tujuan, visi dan misi institusi. Kemudian diturunkan ke Program kerja tahunan. Dalam program kerja tahunan, program lebih dijabarkan secara terperinci berupa kegiatan kegiatan yang akan dilaksanakan sampai ke anggaran biaya yang diperlukan. Sayangnya tidak semua dosen terlibat dalam merencanakan Renstra, jadi tidak semua dosen tahu tentang isi Renstra tersebut, sedangkan dosen merupakan personil yang paling memungkinkan untuk menanamkan pendidikan karakter kepada mahasiswa.

Pada tahapan Pengorganisasian, Ramayulis menyebutkan bahwa pengorganisasian merupakan proses penentuan struktur, aktifitas, interaksi, koordinasi, desain struktur, wewenang dan tugas secara jelas. Dalam bidang manajemen pendidikan, pengorganisasian adalah pembagian tugas terhadap orang - orang yang terlibat dalam pendidikan, ( Arifin.2019). Menurut Hidayat dan Michali (2015) Pengorganisasian adalah proses pembagian tugas kepada personil dalam suatu intitusi yang dalam oelaksanaannya diberikan wewenang dan tanggungjawab untuk mendapatkan tukuan yang efektif, efisien dan produktif (Hasanah,2020).

Baik di Politeknik Al Islam maupun di UIN SGD Bandung sebenarnya sudah melaksanakan pengorganisasian sesuai dengan teori yang sudah disebutkan diatas, yaitu dengan memetakan tugas tugas kepada beberapa personil, tetapi karena sumber daya yang terbatas, maka pembagian tugas diberikan kepada personi yang tersedia, walapun ada beberapa personil yang tidak sesuai dengan kompetensi, minat dan bakat yang dimilikinya. Untuk menangani masalah ini, Politeknik Al Islam telah merekrut beberapa karyawan baru yang sesuai dengan kompetensinya.

Pada tahapan Pergerakan (Actuating), menurut Hidayat dan Machali (2015) menyebutkan bahwa Actuating atau pergerakan adalah langkah merealisasikan tahapan perencanaan dan pengorganisasian (Hasanah, 2020) Pelaksanaan pendidikan karakter di Perguruan tinggi harus diselaraskan dengan visi dan misi berbasis pada jurusan atau program studi dari perguruan tinggi tersebut. Implementasi pendidikan karakter di perguruan tinggi (LPTK) dilaksanakan terintegrasi dengan tiga jalur, yaitu perkuliahan, manajemen perguruan tinggi, dan kegiatan kemahasiswaan. Nilai-nilai karakter yang diterapkan adalah dengan memilih nilai-nilai inti (core values) yang akan dikembangkan dan dilaksanakan pada masing-masing jurusan atau program studi tersebut.(Hasanah,2013) 
Penyelenggaran pendidikan karakter di Politekni Al Islamdan UIN SGD Bandung sudah berjalan dengan sesuai dengan teori yang sudah disebutkan diatas karena sudah disesuaikan dengan visi dan misi yang teringrasikan dengan mata kuliah manajemen perguruan tinggi dan kemahasiswaan hanya belum ada pedoman mengenai nilai nilai karakter inti yang akan ditanamkan kepa mahasiswa,

Tahapan selanjutnya dari manajemen pendidikan karakter adalah controlling atau pengawasan, Tahapan ini harus dilaksanakan secara berkelanjutan agar pelaksanaan pendidikan karakter dapat berjalan sesuai dengan perencanaan yang sudah dibuat dan tujuan yang sudah disepakati.Setelah controlling.

Robbins dan Coulter (2012) menjelaskan: "Management involves coordinating and overseeing the work activities of others so that their activities are completed efficiently and effectively". Manajemen melibatkan koordinasi dan pengawasan kegiatan kerja orang lain sehingga kegiatan dapat dilaksanakan dengan efisien dan ejektif. Malayu (2014) menambahkan bahwa "tujuan koordinasi yaitu sebagai berikut :

1) Untuk mengarahkan dan menyatukan semua tindakan serta pemikiran demi tercapainya sasaran perusahaan

2) Untuk menjuruskan keterampilan spesialis kearah sasaran perusahaan

3) Untuk menghindari kekosongan dan tumpang tindih pekerjaan

4) Untuk menghindari kekacauan dan penyimpangan tugas dari sasaran

5) Untuk mengintegrasikan tindakan kearah sasaran organisasi atau perusahaan

6) Untuk menghindari tindakan overlapping dari sasaran perusahaan".

Rahman (2019) menyatakan bahwa Evaluasi pendidikan karakter meliputi pengawasan dan evaluasi sumatif. Pengendalian sebagai penilaian proses pelaksanaan pendidikan karakter. Dalam pembelajaran, penilaian proses disebut sebagai formatif. Penilaian ini merupakan unsur penting dalam keberhasilan pembelajaran yang efektif.

Tahapan terakhir dari manajemen pendidikan karakter adalah evaluasi. Menurut Rahman (2019) Evaluasi mencakup pengendalian dan penilaian sumatif, Evaluasi adalah proses penilaian pelaksanaan pendidikan karakter. Pada tahapan evaluasi baik Politeknik Al Islam ataupun UIN SGD Bandung sudah melaksanakan sesuai dengan teori yang dilaksankan setiap bulan

\section{KESIMPULAN}

Secara keseluruhan Politeknik Al Islam dan UIN SGD Bandung sudah melaksanakan pendidikan karakter yang disesuaikan dengan visi dan misi institusi yang dintegrasikan dengan Tri Darma Perguruan Tinggi yaitu Pengajaran dan penelitian, Peneitian, dan Pengabdian Kepada Masyarakat walaupun belum semuanya, karena keterbatasan sumber daya manusia yang tersedia.

Dalam hal Perencanaan kedua institusi sudah melaksanakan dengan baik yaitu dengan membuat Renstra, begitu pula dalam hal pelaksanaan sudah menyelenggarakan beberapa kegiatan yang menunjang pada pendidikan karakter diantaranya pesantren intensif, mentoring yang diselenggarakan setiap hari minggu, dan pengintegarsian dalam Tri darma Perguruan Tinggi yaitu dengan masuknya pendidikan karakter dalam pembelajaran, penelitian dan Pengabdian Kepada Masyarakat. 


\section{UCAPAN TERIMA KASIH}

Penulis mengucapkan banyak terimakasih kepada semua pihak yang telah mendukung terlaksananya penelitian ini, terutama kepada direksi, dosen agama dan beberapa mahasiswa Politeknik Al Islam Bandung, Ketua Program studi Kimia dan wakilnya, dosen agama dan beberapa mahasiswa Universitas Islam Negeri Sunan Gunung Djati Bandung yang sudah berkenan diwawanacara untuk kepentingan penelitian ini, Semoga Allah SWT membalas kebaikannya.

\section{DAFTAR PUSTAKA}

Anita. Badrun Wagiran (2019). Karakter Religius Pada Mahasiswa Program Pascasarjana Universitas Negeri Yogyakarta. Jurnal Pendidikan Karakter, Tahun IX, Nomor 2, Oktober .

Arifin, Bambang S. (2019). Manajemen pendidikan karakter. CV Pustakan Setia. Bandung.

Harun, Cut Zahri. (2013). Manajemen Pendidikan Karakter. Jurnal Pendidikan Karakter. , Tahun III, Nomor 3, Oktober .

Hasanah, Yenny M. (2020). Implementasi Manajemen Pendidikan Karakter Di Perguruan Tinggi.Jurnal Administrasi Pendidikan.Volume 27 Issue 2, Oktober Hal 310-320.

Hidayat dan Machali. (2015). The Handbook of Education Management (Teori dan Praktik Pengelolaan Sekolah/Madrasah di Indonesia. Jakarta: Prenadamedia Group

Irawatie,aniek. (2019). Education Learning Development of Character Education-Based State Defense. International Journal of Multicultural and Multireligio.Volume 6, Special Issue 2

February, Pages: 27-42

Irhandayningsih, Anna. (2013), Pendidikan karakter di Perguruan Tinggi: Menyikapi Dekadansi Moral di kalangan Generasi Muda, Jurnal Humanika Volume 17 No 1

Pattaro, Chiara. (2016). Character Education: Themes and Researches. An academic Literature Review. Italian Journal of Sociology Of Education.

Raharjo, TJ. (2015). Keefektivan Manajemen Pendidikan Karakter Pilar Konservasi Budaya Melalui Strategi Pembelajaran Inkuiri Sosial Bagi Mahasiswa Jurusan Pendidikan Luar Sekol Vol. 1 No 1.

Robbins, Stephen P., and Mary Coulter. (2012). Management. 11th. Prentice Hall., New Jersey

Setiawan, Deny. (2013). Peran Pendidikan Karakter Dalam Mengembangkan Kecerdasan Moral. Jurnal Pendidikan Karakter, Tahun III, Nomor 1, Februari .

Sudrajat, Ajat. (2011). Mengapa Pendidikan Karakter?. Jurnal pendidikan karakter.

Fakultas Ilmu Pendidikan Universitas Negeri Semarang. Journal Of Nonformal Education.

Sultoni. (2020). Dampak Pembelajaran Berkarakter Terhadap Penguatan Karakter Siswa Generasi Milenial. Jurnal Adminitrasi dan Manajemen Pendidikan.Volume 3 Nomor 2 Juni , Hal : 160-170.

Suparlan. (2017). Manajemen Pendidikan Karakter Berbasis Pembelajaran Pendidikan Agama Islam Di Perguruan Tinggi Umum. Jurnal Humanika, Th. XVII, No. 1. September 2017.

Taufiqur Rahman (2019). Implementasi Manajemen Pendidikan Karakter dalam Pembinaan Akhlak Peserta Didik. Jurnal Pendidikan Islam Indonesia. Volume 4, Nomor 1, Oktober 2019

Warlizasusi, J. (2018). Analisis Perencanaan Strategis, Rencana Strategis Dan Manajemen Strategis STAIN Curup 2015-2019. Jurnal Manajemen Pendidikan Tadbir vol. 2, no. 2, Desember. 